\title{
LA IMPOSIBLE EQUIVALENCIA ENTRE COMUNICACIÓN E INFORMACIÓN
}

\author{
Rosario Segura García: Universidad de Granada (España)
}

\section{Una ardua tarea: definir los términos}

Suele suceder que aquellos términos que son más obvios, por frecuentes o cotidianos, son los más difíciles de explicar, y más arduo resulta si se trata de teorizar sobre ellos. Es el caso del término comunicación, que es el tema por el que comienza esta investigación. Plantearse qué es comunicar, o qué es comunicación parece una pregunta sin fundamento, porque desde el mismo inicio de la pregunta, parece que ya suponemos que podremos comunicarnos, y de hecho lo estamos haciendo. Entonces, la comunicación ¿es fundamento o es fundamentada?

Esta pregunta nos llevaría muy lejos del campo de investigación y no se pretende tampoco caer en una especulación de tipo cartesiano puesto que los objetivos son más sencillos, pero no por eso menos relevantes, ya que de hecho, es anterior la comunicación a la especulación filosófica, pero también es verdad que la reflexión da rasgos distintivos a la comunicación humana.

Esta aparente paradoja: buscar el fundamento de algo de lo que se está dando por supuesto su utilidad, puesto que está siendo una herramienta en la búsqueda, es un reflejo del carácter paradójico del ser humano. Busca lo que de alguna manera tiene.

En el fondo, se trata de reflexionar, de volverse hacia uno mismo, o lo que hace para encontrar los por qué de las acciones y poder mejorarlas. Esta actitud ha estado presente desde que el hombre era hombre y se paró a pensar: quien soy, por qué estoy aquí, hacia donde voy. Y así surgió el pensamiento intelectual sistemático, la filosofía, y la ciencia y sus aplicaciones prácticas y se desarrollo toda una habilidad como el lenguaje, los símbolos, las lenguas. Y se teorizó sobre el hombre que es lo más difícil sobre lo que teorizar porque es sujeto de la teorización a la vez que objeto, sobre la Naturaleza, sobre lo que hacía el hombre, la Ciencia, la Música, la Letras, el amor, la fe, las palabras, la salud, la enfermedad, las edades de la vida... y un sinfín de vivencias de las que somos sujeto, o de objetos de nuestro alrededor.

Así que la tarea que me propongo realizar es aclarar el mismo término comunicación. En primer lugar, aclararé qué quiero decir cuando menciono el término comunicación y si es similar a información, ya que en diferentes Universidades, se ha optado por nombrar a algunas materias como teoría de la comunicación o de teoría de la información indistintamente. También existe una teoría de la información más, por decirlo llanamente, "computacional" es decir perteneciente al área de las ciencias físicas, matemáticas o a técnicas informáticas. Y parece que no significan lo mismo, y sean campos ajenos, ¿o tal vez estén más relacionadas de lo que parece a simple vista? ¿Está justificada esta indistinción al nombrar esta materia? O lo que es lo mismo, ¿da igual decir comunicación que 
información? Mi opinión es que no es indiferente usar un término u otro, pero tampoco son dos realidades tan ajenas como podría pensarse, ni tan siquiera opuestas como se verá más adelante. En segundo lugar, intentare elaborar una definición de comunicación

\section{Qué nos encontramos cuando empleamos el término comunicación}

\subsection{Un problema ampliamente debatido}

En primer lugar interesa distinguir qué queremos decir cuando empleamos el término comunicación. Acudiendo a diferentes fuentes podemos sintetizar una primera definición que sirva de punto de partida, en la siguiente afirmación:

"Comunicación es un completo conjunto de acontecimientos que se realizan entre un emisor de signos y un receptor de signos a través de un canal determinado siempre que exista entre ellos un determinado consenso de los signos transmitidos, es decir que exista un repertorio de ellos debidamente codificado" (Sánchez Guzmán, 1993, p. 92)

He escogido esta definición como punto de partida porque es lo suficientemente amplia para acoger diversos tipos de comunicación, canales, incluso serviría para aplicarla a fenómenos de "comunicación no humana" el intercambio de iones entre células de un ser vivo, que provocan cambios en el funcionamiento de un órgano. En este caso, hay un canal, hay una codificación ("inconsciente"), hay un mensaje, hay un emisor y un receptor.

Obviamente la comunicación entre dos personas y la comunicación, si se le puede llamar así, entre dos células es bien diferente, pero algo tiene en común y ese algo es lo que ha quedado recogido en la anterior definición. También es útil para referirse a la comunicación entre animales, o a comunicaciones humanas muy diferentes según el canal utilizado: teléfono, carta, internet, televisión, una conversación o una mezcla de todos. Por eso, la tomo como punto de partida y progresar hacia una definición marco que nos sirva de referencia respecto a la investigación que me dispongo a abordar.

Este progreso me propongo hacerlo teniendo en cuenta dos perspectivas principales: la propuesta de teoría de comunicación de Martin Algarra (2005) y el desarrollo alrededor del término información en al ámbito de las Matemáticas y Física, siguiendo la descripción de Shannon (1946). Pienso que la combinación de ambas perspectivas puede aportar un contexto lo suficientemente amplio para enlazar diversas disciplinas que son imprescindibles para comprender de un modo profundo el fenómeno de la comunicación, y que a mi juicio son: la lógica booleana, la neurología, las teorías de la comunicación diseñadas hasta el momento, la psicología, sociología, economía, estética-arte y la filosofía. Como se ve, el ámbito es complejo y propio de un término que es herramienta para casi todo: la comunicación.

Estoy convencida de que el avance en la investigación actual cualquier área pasa por la interdisciplinariedad. Durante siglos, el científico ha progresado en un ámbito 
olvidado los demás. Hasta aquí no habría problema, ya que quizá este "olvido" sea condición de posibilidad de dicho avance en el saber, pero las dificultades surgen cuando se olvida el conjunto del problema, y las relaciones con otros campos. En este último caso, se asiste a un reduccionismo de las posibilidades de saber y conocer, y quizá esto sea lo que haya sucedido en los últimos siglos: y así se asiste a un reduccionismo cientificista, o una crítica exacerbada a la ciencia despojándola de toda validez, provocando un ambiente de perplejidad y pocas ansias de saber.

Es el momento de recoger todos los avances y sintetizarlos, y esto exige un esfuerzo entre científicos, investigadores de diversas áreas. Algo parecido al Ave Fénix que renace de sus cenizas cada quinientos años, debería reaparecer la figura del humanista del Renacimiento en el s.XXI con otras alas, no las del saber individual sino las del saber colectivo, del trabajo en equipo, de interacciones en la red y de la colaboración en proyectos comunes a diversos países, ciencias, y cultura. Este nuevo humanismo no es una actitud que pueda desarrollar un individuo sólo o propia de un genio que surja, sino de una comunidad, la comunidad científica e investigadora, especialmente universitaria, y precisamente por eso, por ser una actitud comunicativa, resulta tan difícil de conseguir.

Se trata de algo no logrado todavía en nuestro entorno más cercano ya que, a mi juicio, la interdisciplinariedad no está todavía bien comprendida ni desarrollada con todo su potencial en la investigación de las áreas de ciencias sociales y humanidades en las universidades las españolas.

\subsection{Perspectivas desde las que abordar el término comunicación}

Para seguir progresando en la definición de comunicación interesa prestar atención a las perspectivas desde las que abordar la comunicación ya que configuran una visión más profunda que la definición inicial que se ha aportado.

Como dice Martín Algarra (2005: 54), hay dos perspectivas que sintetizan las posibles definiciones de comunicación: la perspectiva relacional y la simbólica.

Con la primera se percibe la comunicación como cualquier relación entre dos objetos. Lejos de parecer irrelevante o demasiado amplio, este tipo de perspectiva tiene mucho interés puesto que sirve para ver cómo el intercambio de información entre células por ejemplo, las neuronas, es el soporte para la actividad intelectual, comunicativa, afectiva, etc. y también sirve para vislumbrar cómo es la transmisión de información por los canales digitales soporte también de la comunicación ${ }^{2}$.

La segunda, la perspectiva simbólica, es aquella que considera que la comunicación es una relación con intercambio de contenidos cognoscitivos. El modo de transmisión es mediante representación -símbolo-, por lo que esta perspectiva acota más el significado de comunicación y lo restringe a la comunicación humana. En esta perspectiva, las características de la comunicación son las mismas que las de

\footnotetext{
1 Sigo a Martín Algarra (2005), pp. 53-64, en este análisis del término comunicación.

2 En el epígrafe 2.3 se analiza con más detenimiento lo que es información, y si es equivalente o no a comunicación.
} 
la acción: es humana, social, referencial, compleja y tiene un fin. ¿Qué significado tiene esto?

La primera característica mencionada desde el punto de vista de la perspectiva simbólica, es que la comunicación es humana porque solo es posible para el ser humano, ya que una percepción e interpretación de símbolos debido al carácter de abstracción que supone, exige un desarrollo a nivel cerebral, e intelectual del que sólo dispone el hombre. Además es libre $^{3}$, no está condicionada por elementos bioquímicos, neurológicos, físicos o tecnológicos. Ésto no quiere decir que no tenga absolutamente nada que ver con ellos: la comunicación simbólica dispone de un soporte, el cerebro, que se rige por reacciones bioquímica, y según qué canal emplee, dispondrá también de los músculos fonadores, faciales, de la mano y brazo, o de algo externo como la tecnología.

En segundo lugar, la comunicación desde la perspectiva simbólica es también social porque siempre está orientada a otro, no al yo. Si fuera autorreferencial, dejaría de ser comunicación. Diversos autores han criticado una percepción excesivamente matematizada de la comunicación -como es el caso de la descrita por Shannon y Weaven (1949) y señalan como punto de crítica el olvido de su carácter social.

Todos ellos se refieren a ese carácter social empleando diferentes términos: "unidad de origen y destino"-Charles Osgood (1954: 2)-, "par o díada constituyentes de la comunicación"- Rogers y Kandaid (1981)-, "intersubjetividad"-Hewes y Planalp (1987: 147)-, "yo", "tú" y "nosotros"-Schutz (1964: 161)-, acto de comunicación como acto recíproco de expresión e interpretación"-Rogers y Storey (1987: 830-831), "la comunicación supone una dualidad"-Scherer (1965: 249). Cualquier tipo de comunicación humana es social, si no, no sería tal. Mi opinión es que ambas posturas, la de Shanon y la de los autores mencionados están dialogando desde niveles diferentes, no se trata propiamente de posturas enfrentadas sino de perspectivas diferentes, que se enfrentan si intentan ser exclusivas para una definición de lo que es comunicación.

En tercer lugar, la comunicación es referencial, y esto significa que se conoce algo que de alguna manera es comprendido por el otro, es decir, que se comparte aunque no se logre de un modo absoluto. En cuarto lugar, la comunicación no es algo simple, es un hecho complejo, en el que se elaboran mensajes y se crean significados ${ }^{4}$ en el que la transmisión es una propiedad necesaria ${ }^{5}$. No basta con que dos sujetos interactúen, es necesario que haya un contacto, pero no cualquiera, sino uno que provoque un cambio en el nivel de conocimiento del receptor del mensaje, que se traduce en un acercamiento entre ambos porque vean lo mismo, 0 se provoque un cambio de conducta, es decir, que el receptor de conocimiento quede "afectado" en el sentido amplio de la palabra (no me refiero a algo sensible) por la transmisión del mensaje, si no, no ha habido comunicación. Es decir que la transmisión exige que haya un resultado.

Martín Algarra (2005), p. 60

Frey, Botan, Friedman, y Kreps (1991), p.38

Fisher (1978), p. 7 
Por último, la comunicación es algo actual. El tiempo en el que sucede es en presente. No se trata de un presente medido por relojes, sino se trata de un tiempo "interior", o como diría Bergson, el tiempo como dureé: es un tiempo cualitativo, no cuantitativo, es el tiempo del ser consciente ${ }^{6}$, o como dice Martín Algarra (2005: 67), "el tiempo propio de la acción comunicativa es el presente interior". En la acción comunicativa sucede algo similar a la simultaneidad sin serlo. La expresión y la interpretación no son simultáneas en el sentido de suceder a la vez, aunque cada una en sí misma se dé en presente. Esto es posible porque se trata de un presente interior en el sentido bergsoniano del término. Quien expresa es interpretado en un presente también interior, en un ahora, que no es el ahora del que expresa. El ahora en la comunicación no es simultáneo en el sentido de ser a la vez. El término que mejor explica esta situación es sincronía: cuando ambos presentes coinciden, hay comunicación. Y esta sincronía no es simultánea en el tiempo objetivo y medible, no ocurre a la vez.

\subsection{Acciones de la comunicación en una perspectiva simbólica: Arte, lenguaje y comunicación}

La comunicación comprende dos acciones inseparables: expresión e interpretación. Si falta una de ellas no hay comunicación, son partes esenciales de su estructura. Resulta ilustrador las observaciones de Luka Brajnovic (1979: 57) acerca de lo que considera que es comunicar describiéndola como: "La relación interpersonal entre el informador y el informado para el mejoramiento personal y del entorno del hombre". Aunque el término que utiliza es información ya que se mueve en el ámbito del periodismo, la descripción se refiere a lo que se está tratando de explicar aquí, la comunicación y lo que señala es que comunicar no se reduce meramente a formular un mensaje, hace falta algo más.

Ese algo más queda sintetizado por Martín Algarra (2005: 68) en "algo que compartir", "voluntad de compartir" y "con quien compartir" situaciones que comparecen en las dos acciones de la comunicación: expresión e interpretación. Tradicionalmente podría identificarse estos tres elementos con los términos emisor, receptor y mensaje, pero hay una perspectiva más profunda en este modo de describir la acción comunicativa. En primer lugar, no se trata de algo estático, sino que es dinámico, es acción; en segundo lugar, se emplea el término compartir, y en tercer lugar, se insertan estos tres elementos, si es que podemos llamarlos así, en dos acciones constitutivas de una única acción de comunicar.

El término compartir no es algo ocasional, sino que señala justamente lo que acontece en el acto comunicativo: compartir es algo presente, mientras que transferir, o transmitir, no. A mi juicio está empleado con acierto a la hora de buscar una definición de lo que es la comunicación y además permite comprender mejor la manera de comunicar en una sociedad digital como la que nos encontramos en la que compartir en redes sociales es un modo de comunicarse.

En ocasiones se puede acentuar excesivamente la acción de expresar a la hora de definir lo que es comunicar, pero expresar no es la única acción que forma parte de

Bergson (1970), 1254 
la comunicación y no basta para definirla. El arte también expresa, pero expresa en solitario, como acertadamente señala Martín Algarra (2005: 69). De hecho lo que diferencia el arte de la comunicación no es tampoco la posible ausencia de interpretación, si no la finalidad. La finalidad de la obra de arte acaba en la expresión, mientras que la finalidad de la comunicación concluye cuando se comparte el producto a quien va dirigido. Este, el producto, puede revestir formas de arte, pero está condicionado a ser compartido por alguien es decir, a ser interpretado.

El arte además puede ser comunicado, pero esta posibilidad ya no forma parte de su esencia como señala Lausberg (1975: 375). En un discurso que sea una obra de arte se puede distinguir una duplicidad de esferas: la esfera interna de la obra de arte, y la esfera externa, que es el hecho social. Una obra de arte plasma un estado del espíritu del artista en el producto (expresión). Aunque en los productos que se utilizan en la comunicación quedan también plasmados estados del espíritu de los autores, esto no constituye la finalidad inmediata de la misma. La comunicación, además de expresar e interpretar, puede asumir más funciones pero solo las dos primeras son necesarias para que haya comunicación.

Por ejemplo Kibedi (1989: 32) destaca que un producto que forme parte de un proceso comunicativo, por su expresividad puede tener intención de referirse al logos (transmitir un conocimiento), apelar al pathos (suscitar una emoción) y provocar una acción (ethos). Por ejemplo, una noticia dada en una revista, además de ofrecer conocimiento acerca de un suceso, puede reflejar otras cosas como la emoción de quien escribe, valores éticos que defiende, provocar una reacción emocional en quien lo lee, pero su finalidad inmediata es la primera.

Un escenario interesante es la situación en la que hay voluntad por parte de quien emite el mensaje, de que la interpretación sea incorrecta. En este caso estaríamos ante un caso de manipulación. El producto es el mismo, pero la voluntad en la expresión no es correcta y obliga a una interpretación incorrecta. Resulta relevante profundizar en estas situaciones especialmente en un tipo de comunicación como la publicitaria, y se abordará más adelante.

Tampoco hay que confundir lenguaje y comunicación. Para Coserius (1985: 34-65), se pueden distinguir varias perspectivas a la hora de definir el lenguaje. Se puede considerar el lenguaje como expresión o como reacción a un estímulo, al modo como los animales se hacen indicaciones. También cabe considerar el lenguaje como expresión de un significado, considerar que en el lenguaje lo esencial es materializar un contenido de conciencia, o que la principal función o finalidad del lenguaje es el significado, sería el caso de la definición de lenguaje de Saussure como un sistema de signos. Por último, se puede abordar el lenguaje como comunicación por medio de la expresión.

¿Qué sucede cuando empleamos el lenguaje? Al designar cosas con palabras, quedamos dispensados de tener presentes las correspondientes estructuras perceptivas: al decir "mar" no tenemos la necesidad de tener sensiblemente presente el mar para poder utilizar el término en una conversación o razonamiento. La vida humana sería imposible sin el lenguaje. 
El sonido de las palabras tiene la extraordinaria propiedad de ser, simultáneamente, un movimiento proveniente del sujeto, y -en cuanto audible- un componente del mundo exterior, del mundo de la percepción. Por medio del lenguaje, es posible dirigirse casi sin esfuerzo hacia la cosa objetiva y, al mismo tiempo, percibirla. En tanto que el sonido se dirige al estímulo, crea por sí mismo el símbolo lingüístico que se une fácilmente a ese estímulo; de manera que, cuando se da el sonido, es como si se diera la cosa vista, aunque ésta no se halle presente.

Además, el lenguaje constituye el factor de "socialización" del mundo percibido. Lo objetivo es también intersubjetivo, accesible a todos y manifiesta la conexión entre lenguaje y sociedad.

Pero, ¿Es lo mismo comunicación y lenguaje? Osgood (1954: 2-3) sostiene que en una relación comunicativa, no todo forma parte del mensaje, o lo que es lo mismo, se interpreta no solo el mensaje. Cabe pensar un uso solitario del lenguaje, que sea solo expresión sin interpretación. No son lo mismo, el término comunicación es más amplio que lenguaje pero es indudable que en el caso del hombre, lenguaje y comunicación están unidos de una manera especial.

En resumen: la comunicación no es igual a arte ni lenguaje, aunque puede haber una obra de arte que comunique, y el lenguaje constituir un vehículo de comunicación. La comunicación es un concepto más amplio, es una acción compleja consistente en expresar e interpretar en sentido amplio

\subsection{Comunicación o Información}

Llegados este punto, parece pertinente preguntarse si estamos empleando el término adecuado: comunicación, o deberíamos emplear información. ¿Es lo mismo, hablar de Teoría de la comunicación que de Teoría de la información? Aparentemente no, sin embargo ambos términos están mucho más relacionados de lo que parecen.

Claude Shannon publicó en 1948, la "teoría matemática de la información" en la cual teorizó sobre la relación entre la máquina y la comunicación. Cuando habla de "información" no se refiere tanto a "lo que se dice", sino a "lo que se podría decir". Para Shannon los aspectos semánticos de la comunicación no son tan importantes desde el punto de vista de la ingeniería. Lo realmente relevante para él es que el mensaje se selecciona entre un conjunto de posibles mensajes. De esta manera, la comunicación es transmisión de información de un punto a otro.

El concepto de comunicación adquiere así un contenido físico y cuantitativo. Shannon va llegando a estas conclusiones porque desde un planteamiento de ingeniero, quiere mejorar la transmisión de la información por cable. Y se dio cuenta que para ésto, solo era necesario reestructurar el mensaje en términos de "sí o no", es decir, utilizar una lógica de "verdadero o falso", booleana", o lo que conocemos en

\footnotetext{
George Boole, matemático inglés escribió primero The Mathematical Analysis of Logic, en 1847 y
} posteriormente en 1854, The Laws of Though, en la que trataba con leyes algebraicas las leyes de la lógica 
versión digital, 1-0. Cualquier mensaje podría ser traducido a una serie de 1-0. Cada unidad (1-0) se llamó bit. La cantidad de información que necesitaríamos enviar a un destinatario podía ser medida en bits. Por ejemplo, si una torre vigía tienen que avisar que viene el enemigo, pueden encender una luz para decir que viene el enemigo, y no encenderla para indicar lo contrario. El bit es 1-0. Pero si se quiere decir más información, por ejemplo, si vienen muchos o pocos, a caballo o andando, con cañones o sin ellos, harían falta más bits, una combinación de ellos.

Otra noción clave de Shannon es la de entropía o incertidumbre. Fue la herramienta que revolucionó la información: la medida de información de un canal es la entropía. Por qué esta relación: Shannon buscaba la medida de impredicibilidad de los bits, y la fórmula que dio con la solución fue la misma que Bolztman ${ }^{8}$ encontró para medir el nivel de entropía de un recipiente lleno de gas (fórmula de termodinámica). Descubrió que una formula física en termodinámica es exactamente igual que en la teoría de la información. Aparentemente ¿que tiene que ver la termodinámica con la información? Lo que ha ocurrido tras el descubrimiento de Shannon es que se ve como la termodinámica es en realidad un caso de la teoría de la información. En el fondo, Shannon estaba descubriendo cómo el universo puede estar "codificado".

En la teoría de Shannon, el esquema del sistema general de comunicación se compone de varios elementos que quedan reflejados en el esquema siguiente:

- "Fuente de información" que genera un mensaje o sucesión de mensajes a transmitir al terminal receptor. Esta generación opera por selección del mensaje deseado entre una serie posible de mensajes.

- Transmisor" que opera sobre el mensaje y produce una señal, codificación, para la transmisión sobre el canal.

- "Canal": es el medio utilizado para la transmisión de la señal desde el transmisor al receptor.

- "Receptor" que realiza la operación inversa a la del transmisor reconstruyendo el mensaje a partir de la señal. Es la decodificación.

- "Destino" es la persona u objeto a la que va dirigido el mensaje.

- "Ruido", que son las perturbaciones de la transmisión que provocan distorsiones y errores con la consecuente incertidumbre indeseable.

Pese a las apariencias, este modelo más que con la comunicación social, se emparenta con las ciencias de la vida: la biología y la genética. Tanto la fuente como el destino pueden ser personas, maquinas, órganos biológicos, el caso es que el modo de transmitir información, de codificarla y decodificarla sigue el mismo esquema, y eso constituye el brillante descubrimiento de Shannon, ya que conociendo esto, es fácil mejorar la transmisión de comunicaciones pero es que

proposicional. Esta lógica ha sido utilizada de modo general en el diseño electrónico. También se puede utilizar en el análisis de cómo funcionan los circuitos en computadoras.

8 Ludwig Boltzmann, físico austriaco, fue un teórico de la mecánica estadística y descubridor de la constante que lleva su nombre, concepto fundamental en la termodinámica para medir la entropía en términos estadísticos. Para él, le entropía tiende a incrementarse siempre y la fórmula que la mide es: $\mathrm{S}=\mathrm{k}$. $\ln \mathrm{W}$, en donde $\mathrm{S}$ es la entropía, $\mathrm{k}$ es una constante que lleva su nombre, y $\mathrm{W}$ es el número de microestados posibles para el sistema. 
además, ha llegado a ser un buen instrumento para conocer mejor el funcionamiento de la biología en los seres vivos.

En 1943 Erwin Schrödinger, en su libro ¿Qué es la vida? utiliza este concepto de información para explicar los modelos de desarrollo del individuo contenidos en los cromosomas. El concepto de información fue fundamental para la biología en la explicación del ADN como soporte de la herencia en 1944, para el descubrimiento de su estructura de doble hélice en 1953 y, desde entonces, para todos los trabajos sobre códigos genéticos. Se trata de una metáfora desde la cual los propios científicos interpretan la "realidad" que investigan, y una metáfora que ha tenido grandes consecuencias como por ejemplo, el anuncio de la "decodificación" del "código genético" del genoma humano (26 de julio de 2000).

La interpretación de la vida en términos de información y de códigos y la comunicación entendida como transmisión son aspectos fundamentales en la conformación de la idea actual de la comunicación.

Al hablar de comunicación humana, no se puede olvidar que el cerebro es un elemento indispensable para ella. Ahora bien, resulta imprescindible saber la función de cada cual porque la mera información no es comunicación aunque la comunicación suponga la información. Resulta necesario conocer cómo el mensaje discurre por los diversos canales de comunicación para comprender bien qué es lo que sucede cuando hay comunicación. En el caso de la comunicación publicitaria, que es el caso que nos ocupa, estas consideraciones aportan una perspectiva muy interesante para entender mejor como actúan los mensajes publicitarios en el espectador o por qué algunos son más efectivos que otros. De ahí que forme parte de nuestra investigación una profundización en la neurología de las emociones.

\subsection{Definición de comunicación}

Con los aspectos abordados hasta ahora: perspectivas desde donde analizarla (simbólica y relacional), y tras haber matizado el termino información, se puede concluir que:

La perspectivas relacional y simbólica, y todas y cada una de las características de ésta última descritas son importantes para comprender el fenómeno de la comunicación que pretendo investigar y las tendré en cuenta para el trabajo que me propongo llevar a cabo. No se trata de optar por un modelo más simbólico o por uno meramente interactivo, material, sino de acoger las dos perspectivas (simbólica y relacional) y realizar una síntesis, pues la comunicación humana que es acerca de lo cual vamos a investigar en una de sus posibilidades como comunicación publicitaria, supone las dos perspectivas, no como dos elementos ajenos y extraños entre sí, sino como dos niveles que se necesitan mutuamente.

El término información no es ajeno a comunicación, es un nivel de ésta, perteneciente al aspecto relacional, no al simbólico.

Lo que quiero decir es que en esta consideración de la comunicación humana, se echa el ancla en una antropología en la que el ser humano no es un puzle de piezas 
separadas, sino más bien un organismo con diversos niveles de vida, desde lo más material como el intercambio de iones entre las células de la sustancia gris del lóbulo frontal, a lo más inmaterial, como la interpretación de un sistema de signos emitidos por un individuo, en la que participan todos los niveles de modo aunado.

Entonces, qué es comunicación: a mi modo de ver, la comunicación es una acción compleja, social y por tanto interactiva, que supone expresarlo e interpretar algo por sujetos diferentes, en los que se traduce la expresión e interpretación a uno o más soportes materiales (cerebro humano-sentidos, y/o tecnologías) que actúan como medio. Lo radical de la comunicación es que es una acción que requiere de otros, es social, y que este tipo de acción supone es un soporte material que se rige según la teoría de la información de Shannon. Como se ve el lenguaje formaría parte solo de un tipo de comunicación (lingüística, utilizando un sistema de signos), pero no sería la única, aunque sí la más propiamente humana.

\section{Referencias}

BERGSON, H. (1970). Oeuvres. Pressesk, Universitaires de France: París.

BRAJNOVIC, L. (1979). El ámbito científico de la información. Eunsa: Pamplona.

BRETON, P. (2000). La utopía de la comunicación. Nueva Visión: Buenos Aires.

BRYSON, L. (ed.), The communication of ideas, Harper and Brothers: New York.

BURKE, K. (1969). A Grammar of Motives, University of California press: Berkeley.

COSERIU, E. (1985). El hombre y su lenguaje. Gredos: Madrid.

FISHER, B. A. (1978). Perspectives of Human Comunication. McMillan: New York.

FREY L.R., BOTAN, C.H., FRIEDMAN P.G., y KREPS G.L. (1991). Investigating Communication. Prentice Hall: Englewood Cliffs.

GERBNER, G. (1956). "Toward a General Model of Communication" en Audiovisual communication review, 4, pp.51-77.

KIBEDI VARGA, A. (1978). Discours, récit, image. Pierre Mardarga Editeur: Lieja

KOTLER, P. y LEE, N. (2001). Marketing en el sector público: todas las claves para su mejora. Pearson Educación: Madrid.

KOTLER, P. y ROBERTO, E. L. (1992). Marketing social. Estrategias para cambiar la conducta pública. Ediciones Díaz de Santos: Madrid.

LASSWELL, H. (1948). "The Structure and Function of Communication in Society", en Comunication in society. Disponible en: www.dhpescu.org/media/elip/The\%20structure\%20and\%20function\%20of.pdf 
LAUSBERG, H. (1975). Manual de una retórica literaria. Fundamentos de una ciencia de la literatura. Gredos: Madrid.

MARTíN ALGARRA, M. (2005). Teoría de la Comunicación: una propuesta. Tecnos: Madrid.

OSGOOD, Ch. y SEBEOK, Th. (1954). "Psycholinguistics and research Problems: A survey of Theory and Research problems" en Journal of Abnormal and Social Psychology, 49, suplemento en Memoria de Morton Prince, pp.1-123.

PERELMAN, Ch. y OLBRECHTS-TYTECA, L. (1989). Tratado de la argumentación. La nueva retórica. Gredos: Madrid

ROGERS E. y KINCAID D.L.(1981). Communicattion networks: Towards a New Paradigm of Research. Free Press: New York.

ROGERS E. y STOREY J.D. (1987). “Communication Campaigns” en Berger Ch. y Chaffee, S. (eds.), Handbook os Communication Science, Sage: Beverly Hill, pp. 817-846.

SÁNCHEZ GUZMAN, J. (1993). Teoría de la publicidad. Tecnos: Madrid

SCHERER R. (1965). Structurer et fondament de la communication humaine. SEDES: París.

SCHMUCLER, H. (1997). Memoria de la comunicación. Biblos: Buenos Aires.

SCHRAMM, W.(1954). "How communication Works" en Schramm, W. The Process and the Effect of Mass. University of Illinois Press: Urbana.

SCHUTZ (1962). "Symbol, reality and Society" en Schutz, A. Collected Papers. Volume I: The problem of Social reality. Martinus Nijhoff: La Haya, pp. 287-356.

SCHUTZ (1964)."Making Music Together. A Study in Social Relationship" en Schutz A. Collected Papers II. Studies in Social theory, Martinus Nijhoff: La Haya, pp.159-178

SHANNON, C. E. \& WEAVER, W (1949). The Mathematical Theory of Communication. University of Illinois Press: Urbana.

SPANG, K. (1991). Fundamentos de retórica literaria y publicitaria. Eunsa: Pamplona. 